\title{
PILATOS: UMA SAGA CARIOCA MÓRBIDA E HILARIANTE NOS ANOS 70
}

Pilatos: a morbid and hilarious carioca account in the 70's

Homero José Vizeu Araújo*

\begin{abstract}
Q
uando Carlos Heitor Cony lançouPilatos em 1974, havia quase sete anos que não publicava um romance. Seu último fora Pessach, a travessia, de 1967, romance em que Paulo Simões, personagem-narrador, era praticamente lançado um tanto contra a vontade em uma aventura guerrilheira contestadora do regime militar. O livro causara polêmica e fora considerado reacionário por setores da esquerda que consideraram difamatórios os trechos em que militantes da luta armada demonstram suas fraquezas e alguma sordidez. Isso no livro escrito em primeira pessoa por Cony, que tinha sido o destemido articulista que desancara o regime militar logo depois de concretizado o golpe. Ao longo de 1964, Cony destacou-se nas páginas do jornal carioca Correio da Manhã por assinar artigos denunciando as arbitrariedades cometidas por aqueles que tinham chegado ao poder. Individualista irremediável, Cony parece ter uma disposição nata para definir qual a opinião reinante a fim de contrariá-la.

Cony, enfim, ao lançar Pilatos já era um calejado polemista, masPilatos vai além da polêmica e beira a provocação mais insana. O livro está repleto de humor obsceno e patético que nos revela um Rio de Janeiro gaiato e também macabro. Macabro e obsceno é o humor de Pilatos, com seu personagem narrador a percorrer a alegre alma das ruas cariocas carregando seu pênis que bóia em um vidro de compota de pêssego Colombo. Aqui o detalhe realista da fruta e da marca do doce é parte do efeito humorístico e patético, mas é também crucial para revelar o caráter
\end{abstract}

* Universidade Federal do Rio Grande do Sul 
documental carioca da narrativa. Se Cony situa a maioria de seus romances no Rio de Janeiro, em nenhum outro a cidade aparece tão deteriorada quando aqui. É como se aquele Leonardo, de Memórias de um sargento de milícias, retomasse suas andanças agora em um romance existencialista de humor negro.

Vale lembrar a epígrafe escapista: E assim me rendi ante a força dos fatos: lavei as minhas mãos como Pôncio Pilatos. (Samba erudito, de Paulo Vanzolini). Ora, Pessach: a travessia desagradara tanto à esquerda por ser uma espécie de epopéia existencialista em que o escritor Paulo Simões (carioca como Cony, com quarenta anos no dia 14 de março, como Cony, fuma cachimbo e é desquitado como Cony, tem um editor vinculado ao Partido Comunista, e o editor de Cony era o célebre Ênio Silveira, da Civilização Brasileira) abandona seu dia-a-dia de escritor razoavelmente bem sucedido para encarar uma acidental e acidentada adesão à aventura guerrilheira contra o regime militar.

Depois desta discussão supostamente séria sobre os dilemas do intelectual brasileiro, vem Pilatos, a saga de Herodes, a piroca flutuante em vidro de compota de pêssego Colombo. Sinal dos tempos, dos anos 70, e não é por acaso que os dois nomes bíblicos dividem a cena. Com a agravante de que o membro mutilado recebeu o nome quando ainda ligado ao corpo, numa homenagem ao rei de Israel que teria ordenado o massacre dos recém-nascidos no célebre episódio do evangelho. No lugar de fazer criancinhas - tarefa para um pênis fértil - o rei Herodes as desfez. Por outro lado, note-se que tanto Pilatos como Herodes são vilões na história de Jesus Cristo. Ambos são autoridades na Palestina: Pilatos é o governante que representa o império romano, enquanto Herodes é o rei israelita. Este persegue o nazareno, aquele lava as mãos diante de sua condenação.

Para quem escrevera aquele precoce epitáfio da esquerda armada que é Pessach: a travessia, o tema em Pilatos circularia entre a desistência dos ideais e o escárnio puro e simples. Seja como for, os limites e as possibilidades do engajamento, tal como foram enunciados e debatidos em Pessach aqui são assunto morto, o interesse em Pilatos é pela indiferença e, como se dizia então, pela alienação. Depois de um intróito que remete à cena final do livro, inicia-se a narrativa que abre com uma discussão do personagem-narrador, que é anônimo, sobre a descoberta e o batismo do próprio pênis.

É muito difícil - ou inútil - datar o início desta história. Ela está começando hoje, aqui e agora, talvez só comece realmente amanhã, mais tarde ainda, no nunca, talvez. Sei que esta história existe, está escrita e inscrita em minha carne, mas creio que ela não teve um início preciso, nem mesmo no dia em que resolvi dar um nome ao meu pau. 
Cometo uma falsidade histórica: a história começa no dia em que descobri a existência de um pau entre as minhas pernas, sem me importar, então, como o fato de não ter ele um nome. $\mathrm{O}$ certo é que custei a descobrir o próprio pau, e mais certo ainda é que vivi muitos anos sem me preocupar em dar-lhe um nome. ${ }^{1}$

$\mathrm{O}$ andamento argumentativo e expositivo sobre o assunto entre o natural e escabroso nos insere em uma dissertação relativamente amena; somos levados a considerar sem preconceito a consciência do narrador sobre seu membro, embora um tanto surpresos com temática tão íntima apresentada sem mais. Na seqüência, a exposição prossegue mas o tom muda um pouco. Depois de examinar outros nomes, entre vara, órgão, carvalho, etc, o narrador prossegue:

Cheguei ao nome de Herodes mais ou menos por acaso. Mais tarde descobri obscuras e óbvias razões para tal nome e emprego. Meu primeiro contato com o nome do rei que mandou matar as criancinhas foi num circo, em Lins de Vasconcelos, que naquele tempo era uma terra de ninguém entre o Méier e o Engenho Novo. Fiquei impressionado com o que vi: um drama incompreensível para a minha idade e ocioso para as minhas preocupações, no qual uma mulher dançava com véus, um homem barbado comparecia apenas com a cabeça numa bandeja, e um outro, meio sobre o balofo, fazia muito barulho dando ordens e gritando imprecações. O que me ficou deste homem em particular e do drama em geral foi um enorme manto vermelho debruado de dourados. Foi este manto vermelho que passou a significar, para mim, tanto a condição de rei como a condição de Herodes.

Um dia, na mais baixa adolescência, enquanto me masturbava, olhei a cabeça do pau e notei que ela estava vermelha demais, granada pronta para explodir. A associação se fez para sempre: rei-vermelho-Herodes-pau. HERODES. Gostei do nome. E parece que o pau também gostou.

1 CONY, Carlos Heitor. Pilatos. 2. ed. Rio de Janeiro: Civilização Brasileira, 1975. p. 5. Todas as citações serão retiradas desta edição. 
Formamos assim - tal como Batman e Robin - uma dupla secreta e dinâmica. Passei a carregar Herodes entre as pernas, provendoo em suas básicas necessidades. Ele crescia em graça, talento e formosura para o que desse e viesse. ${ }^{2}$

O trecho encerra o primeiro capítulo do livro e me parece desconcertante e assombroso. A começar pela disposição filosofante e reflexiva posta a serviço da bobagem, ou da pretensão narcisista masculina, ou ainda da sexualidade crua que ergue a obsessão adolescente a elemento crucial. $\mathrm{O}$ andamento filosofante e sentencioso é muito reforçado pelo ritmo elaborado da frase, que freqüentemente ostenta uma espécie de ritmo binário: "obscuras e óbvias, razões...", "tal nome e emprego...", "drama incompreensível para a minha idade e ocioso para as minhas preocupações...", "dando ordens e gritando imprecações...", "deste homem em particular..." e "do drama em geral...", "tanto a condição de rei como a condição de Herodes".

E o último parágrafo radicaliza o procedimento ao apelar para o imaginário pop, sempre em dupla "tal como Batman e Robin" uma dupla secreta e dinâmica. E aqui a elaboração da frase já explora matéria rebaixada, a dupla de heróis, para rebaixá-la mais ainda, ao compará-la à relação entre membro e dono. Os dois períodos finais são uma espécie de apoteose da vulgaridade em estilo pomposo. A elaboração binária permanece: "Passei a carregar (...), provendo-o em suas básicas necessidades, (...) para o que desse e viesse", com o detalhe nada desprezível da fórmula ternária bíblica (graça, talento e formosura) que enfatiza o desse e viesse. De novo há ironia na passagem. Herodes cresce com os atributos que são da infância de Cristo, perseguidor e perseguido unidos e contrastados na prosa equilibrada e na informação razoavelmente sofisticada de leitor da Bíblia. Fica o enigma sobre o perfil do narrador, que mobiliza o conhecimento dos evangelhos para louvar seu próprio membro.

De resto, narrador anônimo para membro batizado. Mas isto não é tudo. A tal disposição reflexiva em busca do nome adequado revela o dado suburbano carioca que dá brilho mimético ao trecho, afinal o tal espetáculo que inspirou o nome é uma cena de circo que se passa em Lins de Vasconcelos, devidamente registrado enquanto terra de ninguém entre o Méier e o Engenho Novo. O detalhismo da anotação reforça o caráter rebaixado da cena bíblica transformada em vulgaridade apelativa com dança de véus, cabeça na bandeja e o tal Herodes com a cor associada à glande já citada. Embora a retórica e as referências do narrador revelem formação refinada e 
informação adequada, o episódio do martírio de João Batista é referido como se o narrador nada soubesse do assunto. Uma falsa inocência equivalente à do meninoadolescente para quem tratava-se "de um drama incompreensível para minha idade e ocioso para as minhas preocupações".

A situação suburbana sugere ingenuidade e a preocupação obscena do narrador puxa a narrativa para a piada grosseira, enquanto a retórica e a informação bíblica insinuam bom gosto e erudição. O resultado é irônico e provavelmente patético, com o narrador ostentando uma dicção razoavelmente elevada para tratar do conteúdo degradado. Uma espécie de piada vulgar e masculina elaborada com retórica e referências sofisticadas.

Na seqüência narrativa, sempre na cidade do Rio de Janeiro, saberemos como Herodes foi parar no vidro de compota de pêssego Colombo. Ao atravessar a rua em 9 de setembro de $19 . .$. , contando 33 anos de idade e um emprego banal, nosso narrador sente uma dor súbita e apaga, para só acordar em um hospital observado por duas freiras, "que me espiavam, do fundo de uma curiosa caridade". Pouco a pouco, o narrador vai se dar conta de que está mutilado e que na mesinhade-cabeceira, no vidro de compota, encontra-se Herodes. Em breve o personagemnarrador revelará que os pacientes do hospital filantrópico são assassinados pelas gentis freiras com um chá da noite.

Outro fato importante, cuja memória guardo daqueles dias, foi um chá que as freiras serviram. Aquela enfermaria era destinada aos doentes mais ou menos desesperados, ou, pelo menos, em estado desesperador. Todos - segundo a opinião dos médicos e das freiras - deviam ter suas razões para não mais se agarrarem à vida com muito entusiasmo, as freiras cooperavam para que os mais fracos tomassem uma decisão. O suicídio do sujeito que ficara sem os culhões foi um fato abençoado. E como ninguém mais se mancasse, as freiras providenciaram num fim de mês o tal chá, que elas serviram pessoalmente às nove e meia da noite. ${ }^{3}$

A gentileza das freiras assassinas fará com que o narrador trate de abandonar o hospital o mais breve possível e dirigir-se ao pardieiro onde alugava um quarto, do qual será sumariamente despejado levando só a roupa do corpo e Herodes no 
vidro. Começa o périplo patético pelas ruas do Rio de Janeiro com o narrador se submetendo a um conjunto variado de humilhações. Por fim, em um banco da Cinelândia, o narrador indiferente encontra aquele que será seu parceiro até o fim da narrativa, Joaquim dos Passos, um homem de ação e de idéias, a maioria delas absurda. Com pretensões à fama literária, introduzirá no relato desencantado e bem humorado do livro quatro narrativas de sua lavra. Joaquim dos Passos é um atleta sexual, um priápico traído pelas mulheres que tentou a bestiofilia para garantir alguma fidelidade. Acaba traído pela cabra adotada e se vinga matando a tiros a adúltera e o respectivo bode. Dizendo-se um homem feliz, Dos Passos encerra seu relato alucinado sobre as tribulações de um priápico em busca da fidelidade. Tudo isso ainda no banco da Cinelândia.

\footnotetext{
- Arrancou o pau?

- Não. Não precisei apelar para medida tão radical. Posso ver qualquer vulva, de mulher mais bela do mundo, posso ver a vulva da rainha da Inglaterra, da sobrinha do Papa, e não sofro mais. Preocupo-me agora com outras coisas.

- Que outras coisas?

- A literatura. O socialismo, coisas assim. Sou radical de direita. Um fascista, compreende? ${ }^{4}$
}

O detalhe é a conversão à literatura e ao fascismo depois do desencanto amoroso bestiófilo. A opção política reduzida a uma piada extravagante que reduz o debate ideológico e estético à bobagem. E é este priápico incorrigível e masturbatório que levará o personagem narrador adiante, com suas idéias mirabolantes e absurdas. Até porque Dos Passos logo demonstra o maior interesse pelo homem mutilado que carrega Herodes de um lado para o outro. Tornar-se-á um cafetão do membro alheio, imaginando formas de explorar a desgraça do personagem-narrador. Do que resulta uma espécie de dupla cômica de personagens em que o otimismo do atleta sexual fascista corneado contrastará com o ceticismo do narrador mutilado.

Um exemplo paradigmático da relação entre os dois personagens surge ainda na seqüência deste primeiro encontro. Ainda no banco da Cinelândia, Dos Passos convida o narrador para irem ver o nascer do sol. 
Recusei. Não me interessava, em absoluto, o nascer do dia. Mas o homem me arrastou pelo braço e quando percebeu que eu andava com certa dificuldade, quis amparar-me, como se eu fosse um perneta.

- Um momento.

Eu esquecera o embrulho em cima do banco. Voltei, apanhei-o. Ele fez o gesto de quem ia segurá-lo, eu o dispensei da ajuda.

- Não. Fico sempre com ele. Não posso me separar disso. ${ }^{5}$

Note-se o tom fatalista da fala do narrador, que no entanto cede ao convite de Dos Passos e dirige-se para o mar, para ver o nascer do novo dia. Mas pergunta:

- Mas para que um novo dia?

- Para tudo. É o amanhã que chega. E amanhã eu vou fazer uma porção de coisas. ${ }^{6}$

Para os leitores da obra posterior de Cony, é uma delícia identificar na frase de Dos Passos os termos do pai de Cony que conhecemos de Quase Memória, livro de 1996 que o relançou na carreira literária. "E amanhã eu vou fazer uma porção de coisas". Ao que tudo indica, o próprio pai de Cony é a fonte de seus personagens picarescos mais ou menos ousados, sempre em contraste com a perspectiva desencantada dos narradores de seus romances e novelas.

Voltando ao passeio rumo ao novo dia em frente ao mar, o autor encerra o capítulo na altura da frase otimista e nos lança na segunda parte do romance, o que é indicado por página em separado. Ee é no primeiro capítulo da segunda parte do romance que prossegue a caminhada rumo ao amanhecer, que não se apresenta porque nuvens no céu barravam a vista. Ao tentarem retornar para a Cinelândia, os dois vêem-se envolvidos por uma pequena multidão que é, nada mais nada menos, que o conjunto dos figurantes e atores de um filme capitaneados por um diretor e um produtor que trocam acusações na presença de toda a equipe. Dos Passos, é claro, interessa-se pelo evento. "Ele quisera ver o nascer do sol, o sol não nascera, agora via um espetáculo menos comovente mas igualmente interessante para ele. ${ }^{7}$

$5 \quad$ Ibid., p. 57.

6 Ibid., p. 58.

7 Ibid., p. 62 
O diretor alega ser impossível ocorrer a filmagem na ausência do sol, que está encoberto por nuvens, enquanto o produtor diz que as filmagens têm que ocorrer devido aos custos envolvidos na organização da cena.

- Mas não tem sol! - gritou o diretor. - Onde vou arranjar um sol agora?

- O problema é seu! Bote o holofote aqui, tapeie, quebre o galho, faça qualquer coisa! Vocês têm de filmar, aqui e agora! ${ }^{8}$

Dado o tom farsesco do debate, é natural que Dos Passos se disponha a intervir e a oferecer o conteúdo do vidro de compota de pêssego Colombo como solução do impasse. E assim começa a se definir a perfil de Dos Passos como explorador da desgraça do narrador.

O meu companheiro de noite interveio:

- Não há sol mas há uma idéia.

O produtor, que não havia reparado nele, olhou-o com espanto.

- O senhor que vá para o caralho!

- Pois é o próprio que eu proponho.

O diretor deu um grito de júbilo:

- Um caralho no lugar do sol! É genial! ${ }^{9}$

Para quem chegou a esta altura da narrativa, não é propriamente novidade a piada grossa e trocadilhesca com o membro em questão. Mas aqui a piada está a serviço de outra piada maior ainda, digamos. Trata-se de satirizar as intenções de esquerda do diretor-roteirista, que tanto entusiasmo demonstrou pela proposta de Dos Passos, da qual o narrador e dono do vidro tenta timidamente se esquivar, embora ceda ao argumento pecuniário de Dos Passos: "-Vamos ganhar um dinheirinho fácil. A sugestão foi minha, o caralho é seu, vamos rachar a nota." ${ }^{10}$

O resumo da história do filme parece sátira aos roteiros mais delirantes e alegóricos de Glauber Rocha.

8 Ibid., p. 62

9 Ibid., p. 64.

10 Id. 
Por cem cruzeiros, eu cederia o meu vidro de compota para a filmagem. A história do filme, cujo esboço me foi feito na hora, pelo próprio diretor, que também era o autor do roteiro, pareceume bastante confusa, havia um latifundiário, a filha de um operário torturado pela polícia, padres, comunistas, um major do exército americano, dois senadores, três músicos sem emprego, um poeta, duas putas, um homem vestido de Pedro Álvares Cabral, uma escola-de-samba inteira, tudo isto misturado num drama muito complicado e acima dos meus interesses e necessidades. ${ }^{11}$

Enfim, no lugar da cena de adoração ao sol por cinco virgens púberes procedeu-se à adoração do conteúdo do vidro de compota do personagem narrador, cena que incluiria um close do objeto de adoração. Retirado de dentro do vidro de compota, o pênis extirpado não tinha nenhuma qualidade digna de nota, mais parecendo "um pedaço grande de toucinho, derretido numa feijoada", diante do que a atriz principal, vestida de bandeira nacional com estrelas até no ventre e na bunda, protesta: "De cabeça para baixo, não. Eu não vou ficar ajoelhada diante disso." 12 Na seqüência, trata-se de simular uma ereção que garantisse a mínima dignidade a Herodes:

Mais uma vez, foi o meu companheiro de noite que salvou a pátria. Sugeriu que se enfiasse um arame por dentro do pau. A coisa funcionou e o pau conseguiu ficar ereto, duro, lembrando os seus melhores - e impossíveis - dias. ${ }^{13}$

Assim, como o resto do episódio, este último trecho prima pela oscilação entre o rebaixado do padrão lingüístico popular ("salvou a pátria, a coisa funcionou, o pau") e traços cultos ("sugeriu que se enfiasse", "os seus melhores - e impossíveis"). Trata-se de procedimento recorrente em que inclusive aquele andamento binário das páginas iniciais volta a comparecer ("os seus melhores -e impossíveis"). No quadro de humor entre melancólico e lúgubre definido em torno

11 Id.

12 Ibid., p. 65.

13 Id. 
da mutilação do personagem-narrador (Pilatos, o indeferente?), as idéias interesseiras e amalucadas de Joaquim dos Passos dão a nota mais fantasiosa e mesmo otimista. A iniciativa de Dos Passos, afinal, deflagra toda a cena de sátira à intenção crítica do cinema nacional, devidamente rebaixada, na voz do próprio diretor, à condição de resposta ressentida de um suposto incompreendido de esquerda:

- Que maravilha! Isso vai fazer um sucesso desgraçado! Quero ver o que os críticos reacionários vão dizer! ${ }^{14}$

O próprio entusiasmo autolaudatório do diretor desqualifica a pretensão de afrontar o "sistema", reduzido à opinião dos críticos reacionários. Enfim, a oscilação entre registro formal e informal, elevado e popular, já faz parte do quadro grotesco que está sendo montado na obra; grotesco, por sua vez, caracterizado por este humor mórbido e patético do narrador anônimo já então, na segunda parte do livro, tensionado pela patifaria lúbrica de Joaquim dos Passos. Dos Passos, enquanto cafetão de Herodes, fará o contraponto necessário à melancolia atônita de narrador mutilado nos próximos dois terços do livro, o que equivale a dizer que a tensão e a conciliação entre os dois personagens será princípio constitutivo da narrativa e deflagrador da ação. De fato, a morte de Dos Passos encerra a livro.

Por outro lado, a disposição pornográfica e bonachona de Dos Passos a circular pela cidade do Rio de Janeiro nos remete ao mundo de malandros e patifes examinado por Antonio Candido em Dialética da malandragem. Joaquim dos Passos é levado por sua luxúria a enfiar nosso narrador mutilado em mais de uma enrascada, o que culmina na prisão dos dois em uma delegacia no Méier, da qual serão transferidos para uma sórdida cela coletiva. Nestes termos, a ação malandra não rende uma sobrevivência mais ou menos tranqüila, muito antes pelo contrário, com os dois personagens sendo acossados pela fome e violência. Por outro lado, as idéias amalucadas de Dos Passos parecem aparentadas, em chave obscena e agressiva, das idéias de Joaquim Borba dos Santos, o Quincas Borba, aquele vagabundo errante do Rio de Janeiro que já conhecera dias melhores, segundo as Memórias Póstumas de Brás Cubas. Será o prenome idêntico e o eco no plural dos nomes mero acaso? Joaquim dos Passos e Joaquim dos Santos? Embora Quincas Borba, sabemos, tenha por pretensão a fillosofia, enquanto Dos Passos desenvolve vocação ficcional, do 
que dão testemunho os quatro contos inseridos no romance ("O homem e a sua cabra", "O homem que virou macarrão e como tal foi comido", "Mafalda ou amor de perdição" e "Da unha e do lugar onde a punha").

Seja como for, a sordidez e a lubricidade, assim como a solidariedade, são marcas fortes do imaginoso Dos Passos, que, cumpre lembrar, tratou de se apresentar como um priápico fascista, cuja conversão ao fascismo ocorreu depois da decepção amorosa com sua cabra. Traído por todas suas mulheres, nem a bestiofilia o salvou de adultério, daí emergindo a opção pelo fascismo e pela literatura. Convenhamos, é o rebaixamento do rebaixamento, em que a opção estética e política derivam da expectativa bestiófila não correspondida. Fascista, lúbrico e delirante, Dos Passos tem uma certa grandeza que o personagem-narrador reconhece e segue.

Na cela coletiva em que vão parar por culpa da iniciativa de Dos Passos, que inventara o tal violino afrodisíaco com os pentelhos do personagem-narrador, passa-se todo o miolo da narrativa. Defecando na mesma lata sórdida, levando surras mais ou menos aleatórias dos carcereiros, encontra-se um grupo heterogêneo e patético. Sic Transit, velho anônimo, mudo e faminto que está sempre tentando devorar Herodes e que corre sério risco de ser sodomizado pelo insaciável e priápico Joaquim dos Passos. O Grande Arquimandrita, velho careca e bochechudo, defensor enfático da democracia que se agarra vigorosamente à hierarquia, à ordem e à moral. Orador verboso e patife sempre em busca de uma supremacia qualquer. Anticomunista como convém, virá a ser o grande traidor e aquele que conseguirá arranjar-se depois da prisão. Uma vez em liberdade, suas denúncias causarão a morte de Otávio e, indiretamente, a de Dos Passos.

Otávio é o jovem barbudo que se recusa a participar do grupo, insinua-se que seja subversivo e maconheiro, mas demonstrará solidariedade quando da súbita liberdade de todos, o que lhe custará a vida. E por fim, o Chinês, marinheiro que se embebedou na Praça Mauá e foi parar na cela coletiva. Supostamente socialista e drogado, alia-se a Otávio. Não sem antes ser sodomizado pelo insaciável Dos Passos.

Como se vê, o enredo cômico e macabro passa, em larga medida, pelo cárcere arbitrário e promíscuo para definir os tipos que garantem movimento a ser filtrado pela perspectiva desencantada do personagem-narrador. Na prisão, por exemplo, relatam-se os duelos verbais entre Dos Passos e o Grande Arquimandrita, cujo título já dá o tamanho de sua megalomania histriônica. Depois da prisão, não faltará a nota de época nas referências à luta armada promovida por Otávio e seus jovens companheiros contra a ditadura militar. Da perspectiva individualista, patética e cética do narrador, não passa de um esforço vão contra poderes incontrastáveis. Depois da morte de Dos Passos, nem sequer levar Herodes dentro do vidro de compota Colombo faz sentido. 
Com meu vidro embaixo do braço, lá fui eu para o Aterro, e não havia sequer a perspectiva de o sol nascer, teria de esperar muito, a noite estava no início. Perto do mar, senti de repente que o embrulho era um fardo exagerado para carregar pela vida. Não tinha o direito de possuir qualquer coisa: era um homem solitário e mutilado, minha recuperação, minha salvação deveria começar pela consciência de que nada era e de que nada me era devido. Precisava me agarrar à vida, molusco apenas. Morto, de nada eu me adiantava. Vivo, ao menos pisava um chão e tinha o direito de pisar os outros, se fosse o caso. Molusco sem veneno, ridículo, tentando ser cruel. ${ }^{15}$

Na seqüência, o vidro é atirado ao mar e a narrativa acaba alguns parágrafos adiante. No entanto, a promessa de redenção ou salvação enunciada não deixa de ser paradoxal, embora coerente com o supremo despojamento garantido pelo fim de Herodes. Para Cony, um ciclo se encerrara. Ele escrevera a metáfora da época? Na castração do personagem encontra-se, sob a força do AI-5, a castração política do país? É possível, mas o perfil dúbio do narrador, entre o sofisticado do enunciado e a grosseria do conteúdo, não facilita o esforço de identificação.

O autor ficaria vinte e três anos longe da literatura até o retorno triunfal com Quase Memória, em 1996. Pilatos rima com o livro panfletário de 1964, O ato e o fato, reunião de artigos publicados no Correio da manhã contra o golpe de 64 . Cony, uma autor lírico e apolítico, partiu para a denúncia das arbitrariedades do regime que se instalou com a veemência e a coragem que lhe renderam fama nos arraiais de esquerda. Ora, depois deste momento particularmente empenhado, virão anos de recrudescimento do autoritarismo do regime e de desencanto com as opções disponíveis, como fica evidente em Pessach: a travessia. Pilatos traz uma rima para anunciar a ausência de solução, com sua perspectiva niilista, entre lírica, mórbida e satírica. Diante da força dos fatos, cantada pelo samba da epígrafe, o corajoso autor empenhado de 64 renuncia a qualquer missão mais ou menos construtiva e escreve um romance instigante e patético. 


\section{RESUMO}

Este ensaio busca analisar os recursos estilísticos do romance Pilatos, de Carlos Heitor Cony, livro que oscila entre a morbidez, lirismo e humor satírico para expor a trajetória de um personagem castrado na cidade do Rio de Janeiro. Depois de discutir as opções de participação de um intelectual em Pessach: a travessia, Cony escreve um livro sobre a indiferença e o escapismo.

Palavras-chave: romance brasileiro, Carlos Heitor Cony, realismo e humor, Pilatos.

\section{ABSTRACT}

This essay analises the stylistic resources of Pilatos, novel by Carlos Heitor Cony, book that shows morbidness, lirism and satirical humour to introduce the ups and downs of a castrated character in Rio de Janeiro city. After explaining the options and doubts of political engagement in Pessach: a travessia, Cony writes a book about the indifference and the evasion.

Key-words: Brasilian novel, Carlos Heitor Cony, realism and humour, Pilatos.

\section{REFERÊNCIAS}

CONY, Carlos Heitor. Cadernos de Literatura Brasileira. São Paulo: Instituto Moreira Salles, n. 12, set. 2001.

O ato e o fato . Rio de Janeiro: Civilização Brasileira, 1964.

Pessach: a travessia. São Paulo: Cia das Letras, 1997.

Pilatos. 2. ed. Rio de Janeiro: Civilização Brasileira, 1975.

CANDIDO, Antonio . A nova narrativa. In: . A educação pela noite. São Paulo: Ática, 1987. 1993. Dialética da malandragem. In: O discurso e a cidade. São Paulo: Duas Cidades,

SCHWARZ, Roberto. O pai de família e outros estudos. Rio de Janeiro: Paz e Terra, 1992.

SUSSEKIND, Flora. Literatura e vida literária: polêmicas, diários e retratos. Rio de Janeiro: Zahar, 1985. (Brasil - os anos do autoritarismo). 